\title{
Aplicação do Jogo Digital Code Combat no Ensino de Programação aos Alunos do Curso Médio Técnico em Informática
}

\section{Application of the Code Combat Digital Game in Programming Education for Computer Technical High School Students}

\author{
Leandro Santos Passos*aa Jonathan Willian Zangeski Novais ${ }^{\mathrm{b}}$; Louyse Siqueira da Silva Varellac; Allan Gonçalves de \\ Oliveira $^{\mathrm{d}}$; Dahiane dos Santos Oliveira Zangeski ${ }^{\mathrm{c}}$ \\ ${ }^{a}$ Universidade do Estado de Mato Grosso, Pós-Graduação Lato Sensu em Informática na Educação. MT, Brasil. \\ bUniversidade de Cuiabá, Programa de Pós-Graduação Stricto Sensu em Ciências Ambientais. MT, Brasil. \\ 'Universidade de Cuiabá, Curso de Engenheira Elétrica. MT, Brasil. \\ dUniversidade Federal de Mato Grosso, Instituto de Computação. MT, Brasil. \\ *E-mail: passosantos@gmail.com
}

\begin{abstract}
Resumo
O estudo compreendeu a aplicação do jogo digital Code Combat, em sala de aula, com o intuito de verificar como os alunos interagiam com esse jogo visando o aprendizado de programação. A programação é muito importante para o tempo atual e seu ensino e aprendizagem é fundamental nos cursos voltados à Tecnologia da Informação (TI). No entanto, no processo de aprendizagem, muitos estudantes se deparam com dificuldades em raciocinar e abstrair respostas para a solução de problemas encontrados. Neste contexto, a utilização de jogos digitais no ensino de programação tem sido uma estratégia, que visa minimizar essas dificuldades. Assim, foi observada a sua a aplicação, em sala de aula, visando o aprendizado de programação. Trata-se de uma pesquisa com abordagem qualitativa e quantitativa a partir de um estudo de caso, tendo como coleta de dados um questionário aplicado aos participantes. Os resultados mostram que essa abordagem possui boa aceitação pelos participantes e se verificou que os participantes se sentiram motivados a aprender programação com o auxílio do jogo digital e, por isso, consideram uma estratégia importante no ensino de programação, em função da facilidade que muitos alunos já possuem para compreender a dinâmica do jogo digital.
\end{abstract}

Palavras-chave: Jogos Digitais. Code Combat. Programação. Aprendizagem.

\begin{abstract}
The study included the Code Combat digital game application in the classroom in order to verify how the students interacted with this game aiming the programming learning. Programming is very important for our time and its teaching and learning is fundamental in courses focused on Information Technology (IT). However, in the learning process, many students face difficulties reasoning and abstracting answers to solve encountered problems. In this context, the use of digital games in programming teaching has been a strategy that aims to minimize these difficulties. Thus, it was observed its application in the classroom aiming at programming learning. This is a research with qualitative and quantitative approach based on a case study with data collection as a questionnaire applied to the participants. The results show that this approach is well accepted by the participants and it was found that the participants were motivated to learn programming with the help of digital game and therefore consider it an important strategy in programming teaching, due to the ease that many students already have to understand the digital gaming dynamics.
\end{abstract}

Keywords: Digital Games. Code Combat. Programming. Learning.

\section{Introdução}

Os computadores e celulares fazem parte do cotidiano da sociedade nos últimos anos, seja em casa, na escola, na faculdade, no trabalho, entre outros. Para que os computadores atendam às necessidades dos usuários é necessário que esses sejam programados. "A programação de computadores é uma tarefa padronizada e bem organizada que exige do programador raciocínio lógico e capacidade de solucionar problemas" (GERALDES, 2014, p.2).

Neste sentido, a programação é muito importante para o tempo atual e seu ensino e aprendizagem, sendo fundamental nos cursos voltados à Tecnologia da Informação (TI). Sendo necessário abordar assuntos como lógica de programação, bem como resolução de problemas através de sequências lógicas (algoritmos). No entanto, o ensino de programação é alvo de estudos e discussões em relação às dificuldades encontradas para o seu domínio. No processo de aprendizagem, alguns estudantes se deparam com dificuldades em raciocinar e abstrair respostas para a solução de problemas encontrados (RAABE; SILVA, 2005).

Sendo assim, existe um esforço por estratégias, ferramentas e abordagens pedagógicas que possibilitem minimizar as dificuldades no ensino de programação.

Neste contexto, a utilização de jogos digitais, no ensino de programação, tem sido uma estratégia que visa minimizar essas dificuldades, pois esses se constituem como novas mídias que podem atuar como elementos mediadores do processo de construção de distintos conceitos da programação (ALVES, 2008).

Podem ser elencadas algumas das vantagens da utilização de jogos educativos (RAMOS; MARQUES, 2017) como: consolidação, de uma forma motivadora, de conceitos já 
aprendidos; aprendizagem de conceitos de difícil compreensão; desenvolvimento de estratégias de resolução de problemas; tomada de decisões e sua avaliação; dar significado a conceitos incompreensíveis; interdisciplinaridade; participação ativa dos alunos nos seus processos de aprendizagem.

Assim, este artigo possui o seguinte objetivo: verificar a aplicação do jogo digital Code Combat, no ensino de programação, aos alunos do Curso Médio Técnico em Informática.

\section{Material e Métodos}

O estudo compreendeu a escolha do jogo digital e sua a aplicação em sala de aula com o intuito de verificar como os alunos interagiam com esse jogo, visando o aprendizado de programação. Trata-se de uma pesquisa do tipo descritiva exploratória aplicada, tendo como coleta de dados um questionário aplicado aos participantes.

Esta pesquisa foi realizada no ambiente educacional, em uma escola estadual no município de Barra do Bugres-MT, com alunos do Ensino Médio, da modalidade Ensino Médio Integrado à Educação Profissional (EMIEP), Curso Técnico em Informática. A unidade escolar é pioneira e tradicional no ensino/aprendizagem na cidade e, atualmente, possui além da modalidade (EMIEP), a Escola Plena (integral) e o Ensino Médio Inovador (EMI).

O número de alunos que participaram da pesquisa foi de 22. Eles fazem parte de $2^{\circ}$ ano, possuem conhecimentos em linguagem de programação estruturada e têm entre 16 e 17 anos de idade.

O jogo digital aplicado foi o Code Combat. Este jogo é mantido por uma comunidade open source de colaboradores presentes em diversos países. De acordo com o site oficial ${ }^{1}$, Code Combat é um jogo que fornece sobre a jornada de um jogador, enigmas bem desenhados, e a habilidade para enfrentar desafios com ação e confiança. Possui, ainda, um robusto mecanismo de digitação de código, que ajuda alunos iniciantes e avançados tanto na escrita quanto na validação do código. A Figura 1 mostra a interface do jogo. Pode-se ressaltar que o estilo de jogo o caracteriza como um RPG ${ }^{2}$.

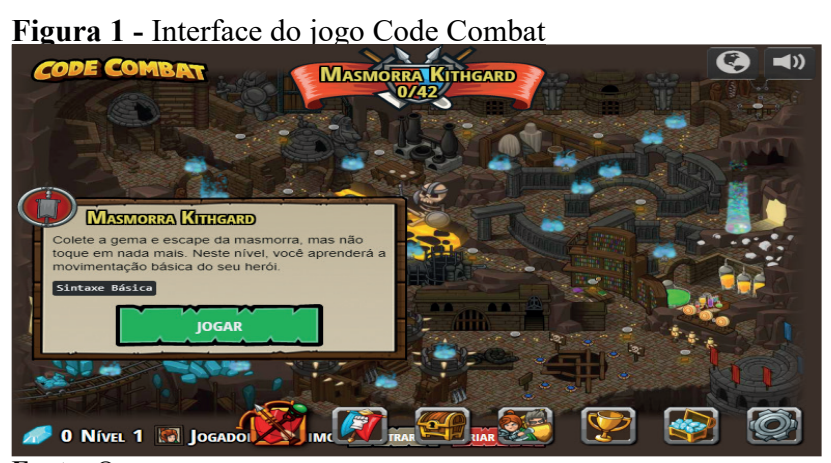
Fonte: Os autores.

Na Figura 2 se pode visualizar que a tela do jogo é dividida para que jogador realize a digitação do código de um lado direito e possa ver o resultado desse, através da ação do personagem previamente escolhido no lado esquerdo, ou seja, se o jogador digitar o código certo, ele avança no jogo e a história acontece.

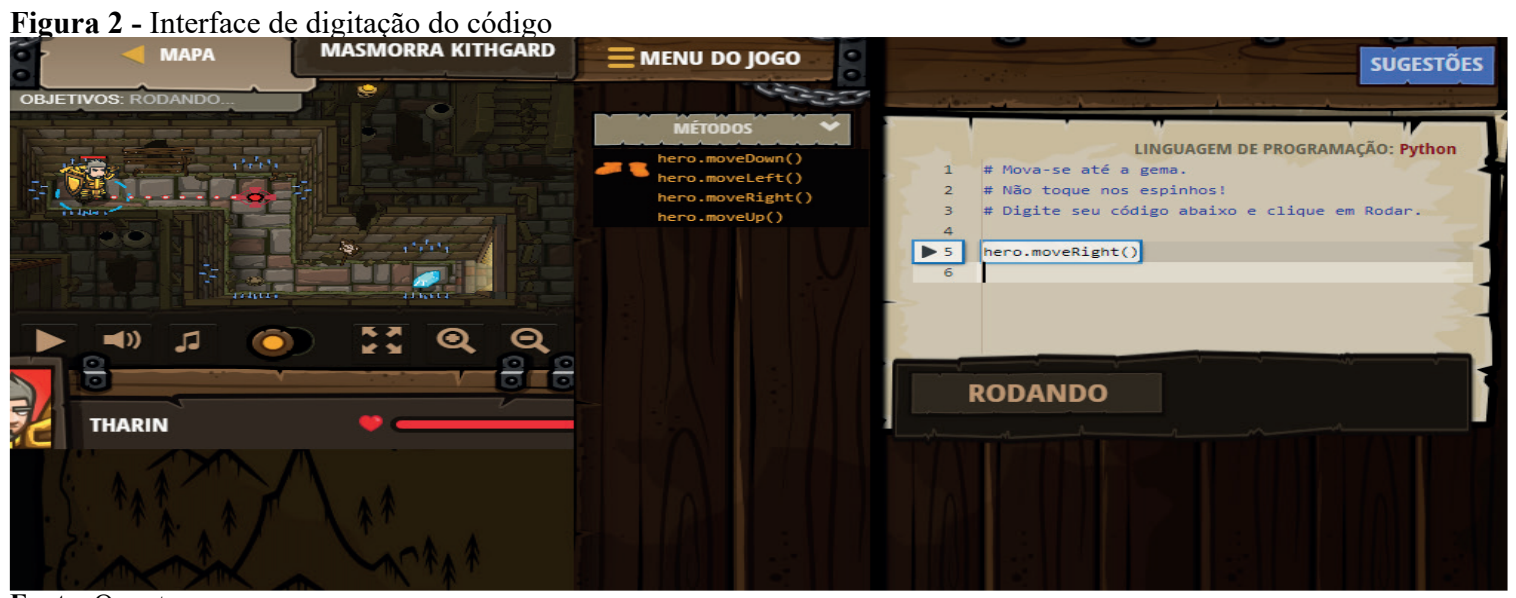

Fonte: Os autores.

Em função dessas características e relevância, o jogo digital Code Combat foi utilizado nesta pesquisa. Após o processo de escolha do jogo, foi realizada a aplicação do jogo em sala de aula.

No primeiro momento foi explicado aos alunos sobre o jogo e qual o objetivo do mesmo. Ficou definido que eles iriam interagir, por um tempo determinado, com o jogo e toda essa interação sem interferência do professor, ou seja, desde a tela inicial até a área de digitação do código.

Em função da limitação no número de computadores, os alunos formaram duplas. Durante a execução foi possível perceber o engajamento e a concentração dos alunos, como mostra a Figura 3. 

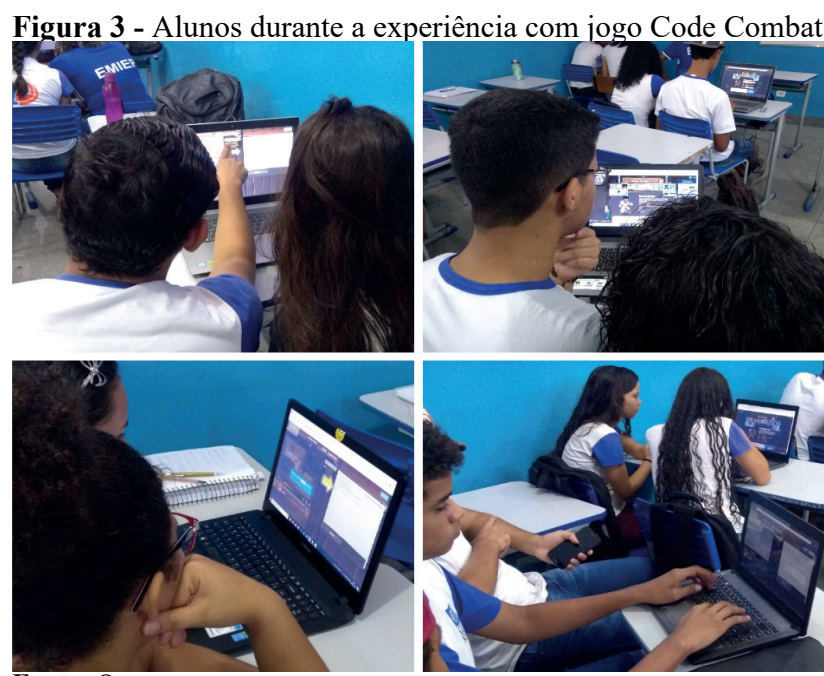

Fonte: Os autores.

Após esse momento, foi aplicado um questionário acessado pelos alunos por meio da tecnologia Google Formulários e os resultados são apresentados na próxima seção. O questionário proposto possui sete questões fechadas (objetivas), conforme descrição a seguir:

1) Você gosta de jogos digitais no seu dia a dia?
( ) $\operatorname{Sim}$
( ) Não
( ) Mais ou menos

2) Em relação a interface do jogo Code Combat utilizado você ficou.

( ) Muito satisfeito

( ) Pouco satisfeito

( ) Mais ou menos satisfeito

( ) Pouco insatisfeito

( ) Muito insatisfeito

3) As explicações e ajuda do jogo Code Combat são de fácil entendimento.

( ) Concordo totalmente

( ) Concordo parcialmente

( ) Não concordo nem discordo

( ) Discordo totalmente

( ) Discordo parcialmente

4) Com a utilização do jogo Code Combat é possível compreender conceitos de programação com mais facilidade.

( ) Concordo totalmente

( ) Concordo parcialmente

( ) Não concordo nem discordo

( ) Discordo totalmente

( ) Discordo parcialmente

5) Durante a experiência com o jogo Code Combat, me senti mais motivado e desafiado a aprender programação.

( ) Concordo totalmente

( ) Concordo parcialmente

( ) Não concordo nem discordo

( ) Discordo totalmente

( ) Discordo parcialmente

6) Por meio dessa experiência, considero a utilização de jogos digitais uma estratégia importante na aprendizagem de conceitos de programação.

( ) Concordo totalmente

( ) Concordo parcialmente

( ) Não concordo nem discordo

( ) Discordo totalmente

( ) Discordo parcialmente

7) Recomendaria para outras turmas a utilização de jogos digitais para o ensino de programação.
( ) Concordo totalmente

( ) Concordo parcialmente

( ) Não concordo nem discordo

( ) Discordo totalmente

( ) Discordo parcialmente

Destas questões, as três primeiras visam avaliar a interação dos alunos com o jogo e as quatro últimas buscam verificar a importância no ensino de programação.

\section{Resultados e Discussão}

Com a análise dos dados coletados, foram gerados os gráficos e suas discussões a seguir.

A primeira pergunta foi referente ao gosto por jogos no dia a dia dos alunos. Todos os alunos gostam de jogos digitais no seu cotidiano. Destes, 90,9\% responderam "Sim" e 9,1\% "Mais ou menos".

Isso ocorre, porque jogos como lazer são partes integrantes da construção da cultura desta geração, como cita Azevedo (2012).

Observa-se, na Figura 4, as respostas referentes à questão 2 do questionário. Essa questão mede o grau de satisfação dos alunos em relação à interface do jogo. Mais da metade, totalizando 63,6\% respondeu que está "Muito satisfeito". Outros 22,7\% apontaram que estão "Pouco satisfeito" e 9,1\% mais ou menos satisfeitos. Apenas um aluno respondeu está "Muito insatisfeito", perfazendo 4,5\% do total.

Figura 4 - Respostas da questão 2 do questionário

2) Em relação a interface do jogo Code Combat utilizado você ficou: 22 respostas

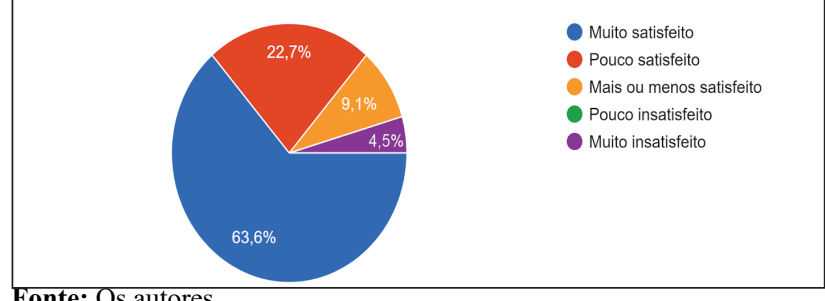

Fonte: Os autores.

A respeito das explicações e ajuda contidas no jogo são de fácil entendimento, os alunos responderam conforme Figura 5. "Concordam totalmente" com a afirmação que representa a opinião de $81,8 \%$ dos pesquisados. Outros 13,6\% “Concordam parcialmente" e 4,5\% "Não concorda nem discorda".

Figura 5 - Respostas da questão 3 do questionário. 3) As explicações e ajuda do jogo Code Combat são de fácil entendimento. 22 respostas

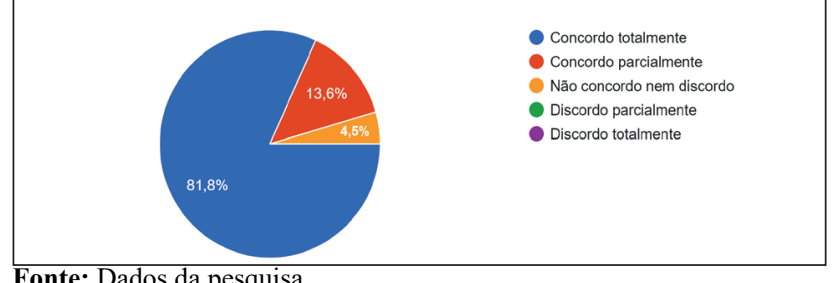

Fonte: Dados da pesquisa.

Em relação à questão 4 do questionário, que se refere acerca da a opinião dos alunos sobre a facilidade que eles 
encontraram em compreender conceitos de programação pelo jogo, encontrou-se como resultado que 72,7\% "Concordam totalmente" e 27,3\% "Concordam parcialmente".

A satisfação da interface por grande parte dos alunos (Figura 5) e o fácil entendimento, conforme respostas da questão 4, são explicados por Raabe, Zanchett e Vahldick (2015) que enfatizam que os objetivos e dicas, por exemplo, estão sempre escritos em azul no início do código, em forma de comentário. Caso o jogador tenha dúvida, basta passar o mouse sobre os métodos que uma caixa de diálogo é exibida com a explicação. Além disso, o jogo possui um botão de ajuda em todas as telas.

A figura 6 representa as respostas da questão 8 do questionário: "Durante a experiência com o jogo Code Combat, me senti mais motivado e desafiado a aprender programação". Mais da metade dos alunos respondeu que "Concordo totalmente", ou seja, um total de 59,1\%. Outros resultados foram: 18,2\% "Concordo parcialmente", 18,2\% "Não concorda nem discordo" e um aluno (4,5\%) "Discordo totalmente".

Figura 6 - Respostas da questão 5 do questionário

5) Durante a experiência com o jogo Code Combat, me senti mais motivado e desafiado a aprender programação.

22 respostas

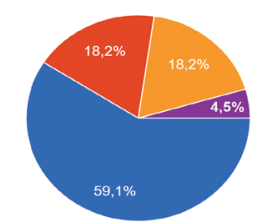

- Concordo totalmente Concordo parcialmente
Não concordo nem discordo Discordo parcialmente - Discordo totalmente

Fonte: Dados da pesquisa.

Rapkiewicz et al. (2006) afirmam que um dos principais problemas no ensino de programação é a falta de motivação dos alunos, aliada com a dificuldade de desenvolver raciocínio lógico para a construção dos algoritmos. Para este resultado, Correia, Cayres e Ramos (2016) afirmam que o Code Combat possui características que promovem a motivação e o desafio em aprender, como: a linguagem de programação é utilizada como meio de comunicação entre personagem e jogador; os desafios progridem gradativamente sendo esses baseados na medida em que o jogador desenvolve maior compreensão na linguagem e; existe um equilíbrio entre o desafio no jogo e o domínio da linguagem de programação necessário à resolução do mesmo.

Em relação aos resultados da questão 6 do questionário: "Por meio dessa experiência, considero a utilização de jogos digitais uma estratégia importante na aprendizagem de conceitos de programação". Das 22 opiniões recebidas, 90,9\% indicaram que "Concordo totalmente" e 9,1\% "Concordo parcialmente".

Dessa forma, a maioria dos participantes considera importante esta estratégia na aprendizagem de conceitos de programação, assim como afirmam Correia, Cayres e Ramos (2016) em relação ao Code Combat.
Para a questão 7 do questionário: "Recomendaria para outras turmas a utilização de jogos digitais para o ensino de programação", o resultado corroborou com os resultados anteriores, em que o jogo digital Code Combat promoveu boas experiências entre os participantes, visto que 95,5\% "Concordo totalmente" e 4,5\% "Concordo parcialmente" que essa prática possa ser levada a outras turmas.

Os resultados desta pesquisa foram semelhantes aos encontrados por Severgnini e Soares (2019), que concluíram que o jogo oferece situações que oportunizam o desenvolvimento do pensamento computacional, e reforçam que a mediação do professor ainda é muito importante para que o aluno internalize as ações realizadas dentro do jogo, reforçando a importância do professor no processo de ensino e aprendizagem.

Assim, fica a reflexão da oportunidade de que os professores de programação têm em usar das tecnologias de informação e de comunicação (TICs), como novas formas de ensinar, porém restando o alerta, conforme salientam Ferreira e Bianchetti (2004), de que estas estratégias são ineficientes se forem adotadas como mero instrumento didático, sem uma preocupação da experiência do aluno.

\section{Conclusão}

Com base na pesquisa realizada, foi possível alcançar o objetivo proposto: verificar a aplicação do jogo digital Code Combat no ensino de programação aos alunos do Curso Médio Técnico em Informática. Verificou-se, então, que o jogo utilizado possui boa aceitação por grande parte dos participantes e que um dos pontos chaves para isso é a presença de uma boa interface, explicações e ajuda. Também foi possível notar que os participantes se sentiram motivados a aprender programação com o auxílio do jogo digital e, por isso, consideram uma estratégia importante no ensino de programação. Os resultados reforçam também a importância do uso das Tecnologias de Informação e Comunicação (TIC) em sala de aula, tirando da interação quadro e aluno da aula expositiva, e mostrando o potencial de aprendizagem quando são usados materiais que ao mesmo tempo sejam lúdicos e ensinem o aluno. Após a realização do trabalho surgiu a ideia de verificar como trabalho futuro a aplicação da estratégia utilizada neste estudo em alunos, que não tenham contato prévio com programação.

\section{Referência}

ALVES, L.R.G. Games e educação: a construção de novos significados. Rev. Port. Pedag., p.225-236, 2008.

AZEVEDO, V. Jogos eletrônicos e educação: construindo um roteiro para a sua análise pedagógica. Renote, v. 10, n.3, 2012.

CORREIA, L.; CAYRES, V.; RAMOS, R. Fundamentos de jogos em abordagens educacionais: um retrato da motivação do aluno jogador. In: SBC - PROCEEDINGS OF SBGAMES, 15., 2016, São Paulo. Anais... Curitiba: SBC, 2016. p. 1202-1204.

FERREIRA, L.; BIANCHETTI, L. As tecnologias da informação 
e da comunicação e as possibilidades de interatividade para a educação. Educ. Contemp., p. 253, 2004.

GERALDES, W.B. Programar é bom para as crianças? Uma visão crítica sobre o ensino de programação nas escolas. 2014. Disponível em: <http://dx.doi.org/10.17851/1983-3652.7.2.105117> . Acesso em: 25 out. 2019.

RAABE, A.L.A.; SILVA, J.M.C. Um Ambiente para Atendimento às Dificuldades de Aprendizagem de Algoritmos. In: CONGRESSO DA SOCIEDADE BRASILEIRA DE COMPUTAÇÃO, 25. São Leopoldo/RS. 2005. Disponível em: $<$ http://www.lbd.dcc.ufmg.br/colecoes/wei/2005/003.pdf $>$. Acesso em: 2 nov. 2019.

RAABE, A.; ZANCHET, G.; VAHLDICK, A. Jogos de programar como uma abordagem para os primeiros contatos dos estudantes com à programação. In: CONGRESSO BRASILEIRO DE INFORMÁTICA NA EDUCAÇÃO, 4., 2015, Maceió. Anais... Porto Alegre: SBC, 2015. p.1485-1494.

RAMOS, V.P.; MARQUES, J.P. Dos jogos educativos à gamificação. Rev. Estud. Invest. Psicol. Educ., p.319-323, 2017.

RAPKIEWICZ, C.E. et al. Estratégias pedagógicas no ensino de algoritmos e programação associadas ao uso de jogos educacionais. Renote, v.4, n.2, doi: https://doi.org/10.22456/1679-1916.14284

SEVERGNINI, L.; SOARES, E. O serious game CodeCombat e o professor como mediadores da aprendizagem do pensamento computacional. In: BRAZILIAN SYMPOSIUM ON COMPUTERS IN EDUCATION. 2019. p. 684. 